\section{Correction: Calculation of baculovirus titer using a microfluidic bioanalyzer}

Two errors appeared in Malde and Hunt, (BioTechniques 36:942-946; June 2004) in the article entitled "Calculation of baculovirus titer using a microfluidic bioanalyzer." The value for viral titer was quoted as 1.26 $\times 10^{6} \mathrm{IU} / \mathrm{mL}$ but should have been $1.29 \times 10^{6} \mathrm{IU} / \mathrm{mL}$, although this is of no statistical consequence to the article's conclusion. Additionally, the reference for the viral titer equation is incorrect (Reference 10, Berns and Giraud). The correct reference is as follows: Amiss, T.J. and R.J. Samulski. 2001. Methods for Adeno-Associated VirusMediated Gene Transfer into Muscle. Methods in Molecular Biology, vol. 175: Genomics Protocols, Chapter 27. Humana Press, Totowa, NJ. The authors regret these oversights. The PDF version of the article, available at http://www.BioTechniques.com, has been corrected.

\section{Erratum: Robust dosage (RD)-PCR protocol for the detection of heterozygous deletions}

An omission of text occurred in Nguyen et al., "Robust dosage (RD)-PCR protocol for the detection of heterozygous deletions"(BioTechniques 37:364-370; September 2004) in the final paragraph on page 364 . The correct text is:

$R D-P C R$ was also tested in a prospective study in hemophilia A families to detect heterozygous deletions in X chromosomal segments. RD-PCR assays were designed for exons 6 and 7 of the factor VIII gene. Eight females from two hemophilia A families were tested, and two female deletion carriers were found and confirmed when deletion junctions were characterized (Figure 2). Recently, six RD-PCR assays were developed for exons in the factor IX gene.

In conclusion, RD-PCR has many advantages, including (i) high accuracy and consistency; (ii) each assay can be validated without known heterozygous deletions as positive controls; (iii) very rapid development and validation of new assays; (iv) utilization of a generic endogenous internal dosage control to eliminate preparation and manipulation errors; (v) detection of gene dosage over a wide dynamic range; (vi) tolerance toward genomic DNA of variable quality (J. Shi, Q. Liu, V.Q. Nguyen, and S.S. Sommer, submitted); and (vii) uniform and unbiased performance across regions of variable sequence context and GC content.

We regret this omission. The PDF version of the article, available at http://www.BioTechniques.com, has been corrected.

\section{Erratum: Liquid gel amplification of complex plasmid libraries}

Two misprints appeared in Elsaesser and Paysan, "Liquid gel amplification of complex plasmid libraries" (BioTechniques 37:200, 202; August 2004). The first step of the protocol listed in Table 1 on page 200 should read in part "prepare $1 \mathrm{~L}$ of the appropriate amplification medium" instead of "prepare a 1:1 ratio of the appropriate amplification medium." In the last paragraph on page 202 , the reference to " $15: 1$ of amplification medium" should instead read "15 L of amplification medium." We regret these errors. The PDF version of the article, available at http://www.BioTechniques.com, has been corrected. 